\title{
Artificial Cultivation System for Gastrodia spp. and Identification of Associated Mycorrhizal Fungi
}

\author{
Chie Shimaoka ${ }^{1}$, Hirokazu Fukunaga ${ }^{2}$, Seishu Inagaki $^{3} \&$ Shinichiro Sawa $^{1}$ \\ ${ }^{1}$ Department of Science, Graduate school of Science and Technology, Kumamoto University, Kurokami, Japan \\ 2 Tokushima-cho, Tokusima, Tokushima 770-0852, Japan \\ ${ }^{3}$ Isehara, Kanagawa, Japan \\ Correspondence: Shinichiro Sawa, Department of Science, Graduate school of Science and Technology, \\ Kumamoto University, Kurokami 2-39-1, Kumamoto 860-8555, Japan. E-mail: sawa@kumamoto-u.ac.jp
}

Received: August 21, 2017

Accepted: September 11, 2017

Online Published: September 16, 2017

doi:10.5539/ijb.v9n4p27

URL: https://doi.org/10.5539/ijb.v9n4p27

\begin{abstract}
The Orchidaceae are the largest and most diverse family of flowering plants on earth, and include some of the most important horticultural plants. While mycoheterotrophic orchids belonging to the genus Gastrodia are known to be provided with carbon through mycorrhizal fungi, the relationship between the plants and fungi is poorly understood. Furthermore, it is challenging to cultivate Gastrodia spp. in vitro. In this study, we present an efficient method for germinating Gastrodia pubilabiata $(G p)$, Gastrodia nipponica $(G n)$, and Gastrodia confusa (Gc) plants in vitro, which results in the production of a protocorm and tuber, as under natural conditions. The $G p$ and Gc plants produced flowers 126 and 124 days after germination, respectively, and set seed under our artificial conditions. In addition, $G p$ plants flowered up to three times a year from a single tuber. Using our artificial cultivation system, we identified some of the mycorrhizal fungi associated with these plants. Gastrodia spp. appear to obtain carbon from many kinds of mycorrhizal fungi. Our artificial cultivation method is a rapid and efficient means of growing Gastrodia spp. In addition to having applications in research and commercial nurseries, this method could be used to conserve Gastrodia spp. in ex situ, many of which are endangered.
\end{abstract}

Keywords: artificial cultivation, Gastrodia confusa, Gastrodia nipponica, Gastrodia pubilabiata, mycoheterotrophic plants, Orchidaceae

\section{Introduction}

Mycoheterotrophic plants (MHPs) have a mutualistic relationship with mycorrhizal fungi, which provide the plant with carbon (Smith \& Read, 2008; Kinoshita et al., 2016). Most MHPs have a high fungal specificity (reviewed by Bidartondo, 2005), whereas others interact with a variety of species (Roy et al., 2009; Hynson \& Bruns, 2009). Obligate MHPs, which include about 530 species, do not produce functional chloroplasts and are completely dependent on their associated mycorrhizal fungi as a source of carbon.

Gastrodia (Orchidaceae) is a genus of obligate mycoheterotrophic orchid that is distributed in warm areas of Madagascar, Asia, and Oceania (Paul \& Molvray, 2005; Chung \& Hsu, 2006). 16 species of Gastrodia (Orchidaceae) are indigenous to Japan, including G. elata $(G e), G$. javanica, G. boninensis, G. confusa (Gc), G. nipponica (Gn), G. pubilabiata (Gp), G. shimizuana, G. gracilis, G. clausa, G. takeshimensis, G. uraiensis, G. fontinalis, G. flexistyloides, G. kuroshimensis, G. nipponicoides and G. okinawensis (Tuyama, 1939; Honda \& Tuyama, 1939; Tuyama, 1941, 1952, 1956, 1966, 1967; Garay \& Sweet, 1974; Hatusima, 1975; Sawa, 1980; Tuyama, 1982; Kobayashi \& Yukawa, 2001; Suetsugu et al., 2012, 2013, 2014; Suetsugu, 2012, 2013, 2014, 2015a, 2015b, 2016, 2017).

$G e$ is commercially cultivated, especially in China, as its tuber is used in herbal medicine (Xu \& Guo, 2000). However, there are no reports of other Gastrodia spp. being successfully cultivated for more than one generation. While $G p$ and Gc seeds were germinated and cultured in vitro, using enriched agar medium supplemented with mycorrhizal fungi (Tashima et al., 1978; Umata et al., 2000), the resulting plants failed to flower and/or produce seed.

Some mycorrhizal fungi that associate with Gastrodia spp. have been identified, such as Armillaria of Physalacriaceae, which associates with Ge (Kusano, 1911); Mycena of Mycenaceae, which associates with Gc (Ogura-Tsujita et al., 2009); Marasmius and Campanella of Marasmiaceae, which associate with G. sesamoides 
(Dearnaley \& Bougoure, 2010); and Resinicium of Meruliaceae, which associates with G. similis (Martos et al., 2009).

The natural habitats of $G p, G n$, and $G c$ have been characterized in detail (Sugino, 1983; Sugino \& Suzuki, 1985; Fukunaga et al., 2008). In the current study, we successfully cultivated $G p$, $G n$, and $G c$ in habitat-like artificial environments that were neither sterile nor enriched with nutrients. The artificial cultivation system (ACS) is simple and does not require sterile conditions or expensive equipment. We also identified some of the mycorrhizal fungal species associated with these three Gastrodia species, and observed that different mycorrhizal fungal species can associate with more than one of these Gastrodia species. Our ACS has both research and commercial applications.

\section{Materials and Methods}

In vitro culture was performed in laboratories at Kumamoto, Kanagawa, and Tokushima, Japan. Artificial medium was prepared from $G p$ habitats in Kanagawa, Gn habitats in Tokushima and Kanagawa, and Gc habitats in Kochi and Kanagawa. The medium included a 30-cm long segment of cedar log (Cryptomeria japonica; "cedar medium"), a 30-cm long segment of Castanopsis sieboldii log ("sudazi medium"), or sections of aboveground tissue of the bamboo Phyllostachys edulis ("moso medium"), respectively, and placed in a sealed plastic box with wet gauze and a vinyl sheet lining the inside of the lid (Figure $1 \mathrm{~A}-\mathrm{E}$ ). $G p, G n$, and $G c$ plants were grown in these different media. To promote fungal growth, the medium was surrounded with cedar cones and humus from the floor of a Castanopsis sieboldii forest. Seeds were sown on the surface of the medium as shown in Figure 1F. The plants were grown at $20-25^{\circ} \mathrm{C}, 80-85 \%$ relative humidity, in complete darkness. Seeds were harvested from their natural habitats in Kanagawa and Shizuoka $(G p)$, Tokushima $(G n)$, and Shizuoka $(G c)$, or obtained through self-pollination of plants in the laboratory. The seeds were directly placed in the artificial growth medium.

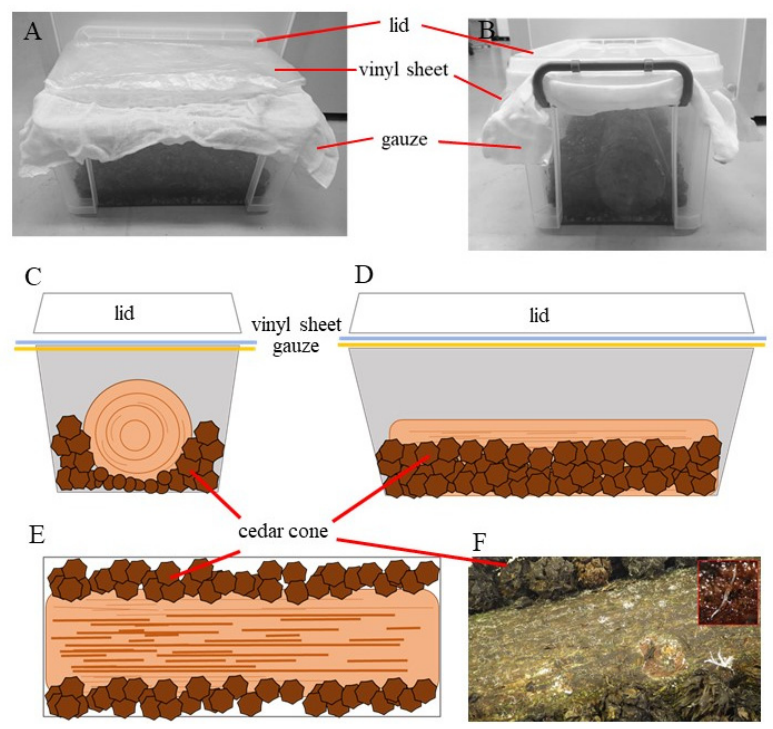

Figure 1. The artificial culture medium kit.

Medium is placed in a sealed plastic box, with wet gauze and a vinyl sheet lining the inner lid (A). To maintain moist conditions, the lid is kept closed except when watering (B). The medium is composed of a 30-cm or section of bamboo (in the case of moso medium) surrounded with cedar cones; side view (C), front view (D), and top view (E). (F) Seeds were sown directly on the medium. Inset shows magnified seed sown on the log.

DNA was extracted from protocorms that formed from the seeds using the CTAB method (Lee et al., 1988; Wu et al., 2001). The internal transcribed spacer (ITS) region of the fungal nuclear ribosomal RNA gene (rDNA) was amplified using the primers ITS1F and ITS4B (Gardes \& Bruns, 1993), using TaKaRa Ex Taq Hot Start Version (Takara Bio, Japan). The PCR mixture contained $2 \mu \mathrm{L}$ of the extracted DNA solution, $0.05 \mu \mathrm{L}$ of Ex Taq polymerase, $10 \mu \mathrm{M}$ of each primer, $0.25 \mu \mathrm{M}$ of each $\mathrm{dNTP}$, and $1 \mu \mathrm{L}$ of $10 \mathrm{x}$ buffer in a total volume of 10 $\mu \mathrm{L}$. The PCR program was performed using an i cycler (Bio Rad, Japan), as follows: initial denaturation at $94^{\circ} \mathrm{C}$ for $5 \mathrm{~min}$, followed by 30 cycles at $94^{\circ} \mathrm{C}$ for $30 \mathrm{~s}, 55^{\circ} \mathrm{C}$ for $30 \mathrm{~s}$, and $72^{\circ} \mathrm{C}$ for $1 \mathrm{~min}$, followed by a final 
elongation at $72^{\circ} \mathrm{C}$ for $7 \mathrm{~min}$. Amplified PCR products were purified using an EconoSpin column (Gene design, Inc.), and the purified PCR product was sequenced. The obtained DNA sequences were subjected to a BLAST search (Altschul et al., 1997). Multiple sequence alignment was performed using ClustalX (Larkin et al., 2007). The GenBank accession numbers of the mycorrhizal ITS sequences analyzed were as follows: Diplomitoporus rimosus, AB907585; Thelepurus membranaeus, NR119985; Trechispora, JF691276; Corticium, KP814404; and Mycena, NR119985.

\section{Results}

\subsection{Artificial cultivation of $G p$}

$G p$ seeds were germinated on cedar medium from 17-55 days after sowing (DAS; Table 1) and developed into protocorms (Figure 2). Root tuber primordia emerged from the base of bracts at the top of the spherical protocorms immediately after the latter formed. Roots also emerged from the sides of the protocorms (Figure 2). One of the roots dominated, even after flowering. Protocorms developed into tubers. The tubers spontaneously stopped developing 4 months after sowing, and the shoots bolted. Flowers opened one month after bolting. Capsules matured and opened 20-30 days after the flowers opened, a little sooner than they typically do in their natural habitat (40-50 days after flower opening). Protocorm formation, tuber formation, root emergence, floral opening, and capsule formation were observed 20-65, 25-80, 30-82, 154-299, and 194-321 DAS, respectively (Table 1).

Table 1. List of seeds, media, and growth rate in our ACS.

We could not confirm some of developments (x). We stopped some cultures, and there is no data (-).

\begin{tabular}{|c|c|c|c|c|c|c|c|c|c|c|c|}
\hline \multirow{2}{*}{$\begin{array}{l}\text { Gastrodia } \\
\text { spp. }\end{array}$} & \multirow[t]{2}{*}{ number } & \multicolumn{2}{|c|}{ habitat } & \multirow{2}{*}{$\begin{array}{l}\text { Experiment } \\
\text { place }\end{array}$} & \multicolumn{7}{|c|}{ Development } \\
\hline & & media & seed & & Sowing & Germination & Protocom & Tuber & Root & Flower open & Capsule \\
\hline$G$ & $\# 2$ & Kanagawa & Kanagawa & Kanagawa & 2012.11 .25 & 2012.12 .20 & 2012.12 .25 & 2012.12 .28 & 2012.12 .30 & 2013.05 .14 & 2013.06 .07 \\
\hline \multirow[t]{21}{*}{ pubilabiata } & & 【cedar】 & & & & 25DAS & 30DAS & 33DAS & 35DAS & 170DAS & 194DAS \\
\hline & $\# 3$ & & & & 2013.04 .23 & 2013.05 .20 & 2013.05 .22 & 2013.05 .30 & 2013.06 .01 & $x$ & \\
\hline & $\# 4$ & & & & & 27DAS & 29DAS & 37DAS & 39DAS & & \\
\hline & & & & & 2013.04 .23 & 2013.05 .10 & 2013.05 .13 & 2013.05 .18 & 2013.05 .23 & $2014.02 .16(1 \mathrm{st})$ & 2014.03 .10 \\
\hline & & & & & & 17DAS & 20DAS & 25DAS & 30DAS & 299DAS & 321DAS \\
\hline & & & & & & & & & & $2014.07 .22(2 \mathrm{nd})$ & \\
\hline & & & & & & & & & & $2014.10 .29(3 \mathrm{rd})$ & \\
\hline & $\# 13$ & & & Kanagawa & 2014.12 .04 & 2014.12 .24 & 2014.12 .28 & 2015.01 .05 & 2015.01 .08 & - & - \\
\hline & & & & & & 20DAS & 24DAS & 32DAS & 35DAS & & \\
\hline & $\# 14$ & & Shizuoka & Kanagawa & 2015.01 .14 & 2015.02 .07 & 2015.02 .08 & 2015.02 .15 & 2015.02 .20 & - & - \\
\hline & & & & & & 24DAS & 25DAS & 32DAS & 37DAS & & \\
\hline & $\# 15$ & & Kanagawa & Kumamoto & 2015.02 .18 & 2015.03 .15 & 2015.03 .17 & 2015.04 .05 & 2015.04 .09 & 2015.10 .28 & - \\
\hline & & & & & & 25DAS & 27DAS & 46DAS & 50DAS & 252DAS & \\
\hline & $\# 16$ & & & Tokushima & 2015.02 .23 & 2015.04 .19 & 2015.04 .22 & 2015.04 .23 & 2015.04 .26 & 2015.10 .25 & 2015.12 .02 \\
\hline & & & & & & 55DAS & 58DAS & 59DAS & 62DAS & 244DAS & 282DAS \\
\hline & \#18 & & self-pollinated & Kanagawa & 2015.04 .18 & 2015.05 .10 & 2015.05 .10 & 2015.05 .15 & 2015.05 .18 & 2016.10 .20 & - \\
\hline & & & in vitro & & & 22DAS & 22DAS & 27DAS & 30DAS & 185DAS & \\
\hline & $\# 20$ & & Kanagawa & Kanagawa & 2015.10 .17 & 2015.11 .27 & 2015.12 .21 & 2016.01 .05 & 2016.01 .07 & $x$ & \\
\hline & & & & & & 41DAS & 65DAS & 80DAS & 82ads & & \\
\hline & $\# 23$ & & Kanagawa & Kanagawa & 2016.11 .12 & 2016.12 .10 & 2016.12 .12 & 2016.12.17 & 2016.12 .19 & 2017.04 .15 & 2017.5.30 \\
\hline & & & & & & 28DAS & 30DAS & 35DAS & 37DAS & 154DAS & 199DAS \\
\hline \multirow{6}{*}{$\begin{array}{l}G . \\
\text { nipponica }\end{array}$} & $\# 1$ & Kanagawa & Tokushima & Kanagawa & 2015.05 .16 & 2015.06 .15 & 2016.06 .17 & 201.06 .20 & 2016.06 .20 & breeding & \\
\hline & & 【cedar】 & & & & 30DAS & 32DAS & 35DAS & 35DAS & & \\
\hline & $\# 2$ & Tokushima & Tokushima & Tokushima & 2015.05 .21 & 2015.06 .03 & 2015.06.05 & 2015.07 .05 & 2015.07 .05 & $x$ & $\times$ \\
\hline & & 【sudazi】 & & & & 13DAS & 15DAS & 45DAS & 45DAS & & \\
\hline & $\# 3$ & Kanagawa & Tokushima & Kanagawa & 2015.05 .20 & 2015.06 .15 & 2015.06 .17 & 2015.06.19 & 2015.06.19 & $x$ & $x$ \\
\hline & & 【cedar】 & & & & 26DAS & 28DAS & 30DAS & 30DAS & & \\
\hline \multirow[t]{8}{*}{ G. confusa } & $\# 1$ & Kanagawa & Shizuoka & Kanagawa & 2014.11.07 & 2014.12 .01 & 2014.12 .10 & 2015.01.08 & 2015.01 .15 & - & - \\
\hline & & 【cedar】 & & & & 24DAS & 33DAS & 62DAS & 69DAS & & \\
\hline & $\# 2$ & & Shizuoka & Kanagawa & 2014.12 .12 & 2014.12 .20 & 2015.01 .16 & 2015.01 .25 & 2015.02 .14 & 2015.07 .20 & 2015.08 .14 \\
\hline & & & & & & 8DAS & 35DAS & 44DAS & 64DAS & 220DAS & 245DAS \\
\hline & $\# 4$ & Kochi & Shizuoka & Kanagawa & 2015.11 .05 & 2015.12 .11 & 2015.12 .18 & 2015.12 .20 & 2015.12 .25 & 2016.10 .10 & $x$ \\
\hline & & 【moso】 & & & & 36DAS & 43DAS & 45DAS & 50DAS & 340DAS & \\
\hline & $\# 6$ & Kanagawa & Shizuoka & Kanagawa & 2016.11 .12 & 2016.12 .12 & 2017.01 .04 & 2017.01 .30 & 2017.02 .03 & 2017.04 .15 & $x$ \\
\hline & & 【cedar】 & & & & 30DAS & 53DAS & 79DAS & 83DAS & 154DAS & \\
\hline
\end{tabular}




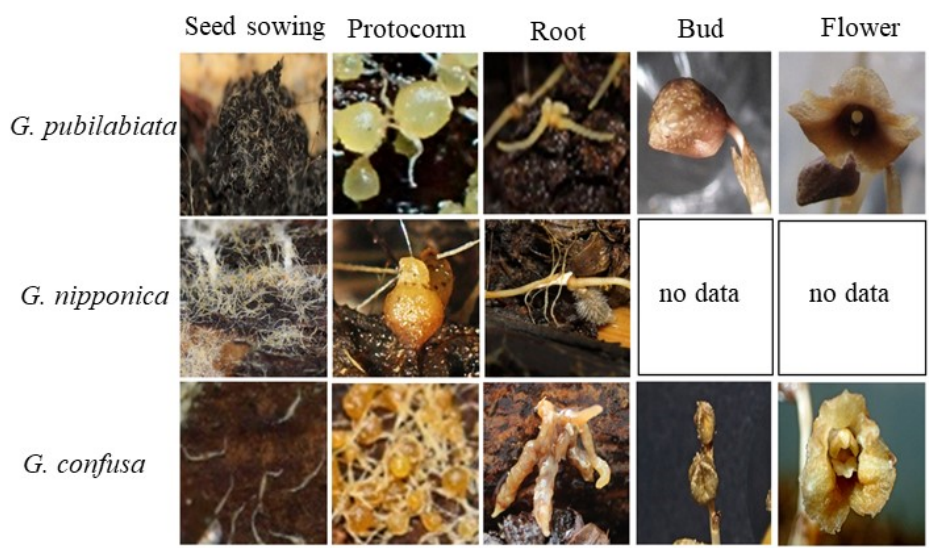

Figure 2. Gastrodia spp. growing steps, from seed sowing to flower opening

Protocorms are produced at 30 days after sowing (DAS), roots are produced at about 40 DAS, buds are generated at about $150 \mathrm{DAS}$, and flowers open at about $160 \mathrm{DAS}$.

The first $G p$ flower opened at 154 DAS. Artificial conditions can accelerate growth and induce early flowering. The largest of several tubers generated in our ACS produced shoots and flowers three times in a one-year period

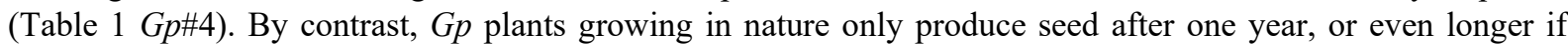
conditions are not ideal. Thus, these plants develop more rapidly in our ACS than they do in their natural habitat, and our ACS is an efficient method for maintaining these plants in vitro.

\subsection{Artificial Cultivation of Gn}

Gn seeds were sown on cedar and sudazi medium, and germinated at 13-30 DAS. Protocorms formet at 15-32 DAS. Tubers and roots emerged at 30-45 DAS (Table 1). While $G n$ tubers did not produce flowers under our cultivation conditions, these plants. developed and grew more rapidly in the ACS than in their natural habitat.

\subsection{Artificial Cultivation of $G c$}

Gc seeds were sown on cedar or moso medium, and germinated at 8-36 DAS. Protocorm formation, tuber formation, root emergence, floral opening, and capsule formation were observed at 33-53, 44-79, 50-83, 154-340, and 245 DAS, respectively (Table 1). Gc seeds sown on cedar medium were viable, giving rise to plants that flowered and set seed. Interestingly, we found that $G c$ and $G p$ were able to grow simultaneously on the same cedar $\log$ (Figure 3). This suggests that the specificity of mycorrhizal fungi is low between Gastrodia spp., and that the same species of fungus can form mutualistic relationships with different species in this genus.
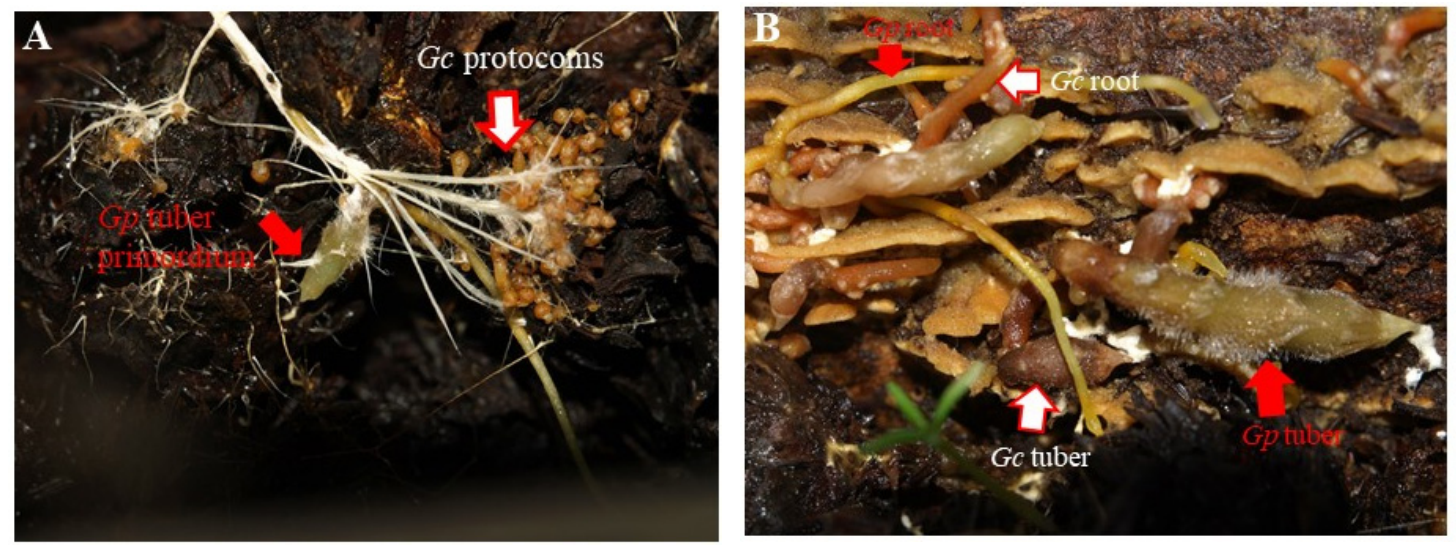

Figure 3. $G p$ and $G c$ can be cultivated together

(A) $G c$ (Shizuoka) can generate protocorms when sharing the same mycelium as $G p$ (Kanagawa). Red arrow: $G p$ tuber primordium. White arrow: $G c$ protocorms. (B) $G p$ and $G c$ grow at similar rates on the same cedar log. Red arrow: $G p$ root and tuber. White arrow: $G c$ root and tuber. 


\subsection{Molecular Identification of Mycorrhizal Fungi}

Using our ACS, we next sought to identify the mycorrhizal fungi associated with Gastrodia spp. based on the internal transcribed spacer (ITS) region of the fungal nuclear ribosomal RNA gene (rDNA). We found that $99 \%$ of the sequenced region using a protocorm sample of $G p$ (cedar medium from Kanagawa) and $G n$ (sudazi medium from Tokushima) matched that of Diplomitoporus rimosus (558bp/559bp identity) and Thelepurus membranaeus (542bp/544bp identity), respectively. These fungi were also detected in the cedar medium or sudazi medium, respectively (Diplomitoporus rimosus, $411 \mathrm{bp} / 412 \mathrm{bp}$ identity, or Thelepurus membranaeus, $548 \mathrm{bp} / 553 \mathrm{bp}$ identity). These results strongly suggest that these fungi are responsible for the successful development of Gastrodia spp in our ACS. While D. rimosus and T. membranaeus are located in the same phylogenetic clade of Polyporales, they are not evolutionarily close to each other (Figure 4).

Furthermore, from $G n$ protocorms, we detected an ITS sequence with significant nucleotide sequence identity to the corresponding regions in Trechispora (509bp/582bp identity) and Corticium (537bp/617bp identity). We also detected an ITS sequence similar to that from Mycena spp. (602bp/604bp identity) as a candidate of mycorrhizal fungi associated with $G c$. These data suggest that Gastrodia spp. can successfully grow in association with a number of different species of mycorrhizal fungi.

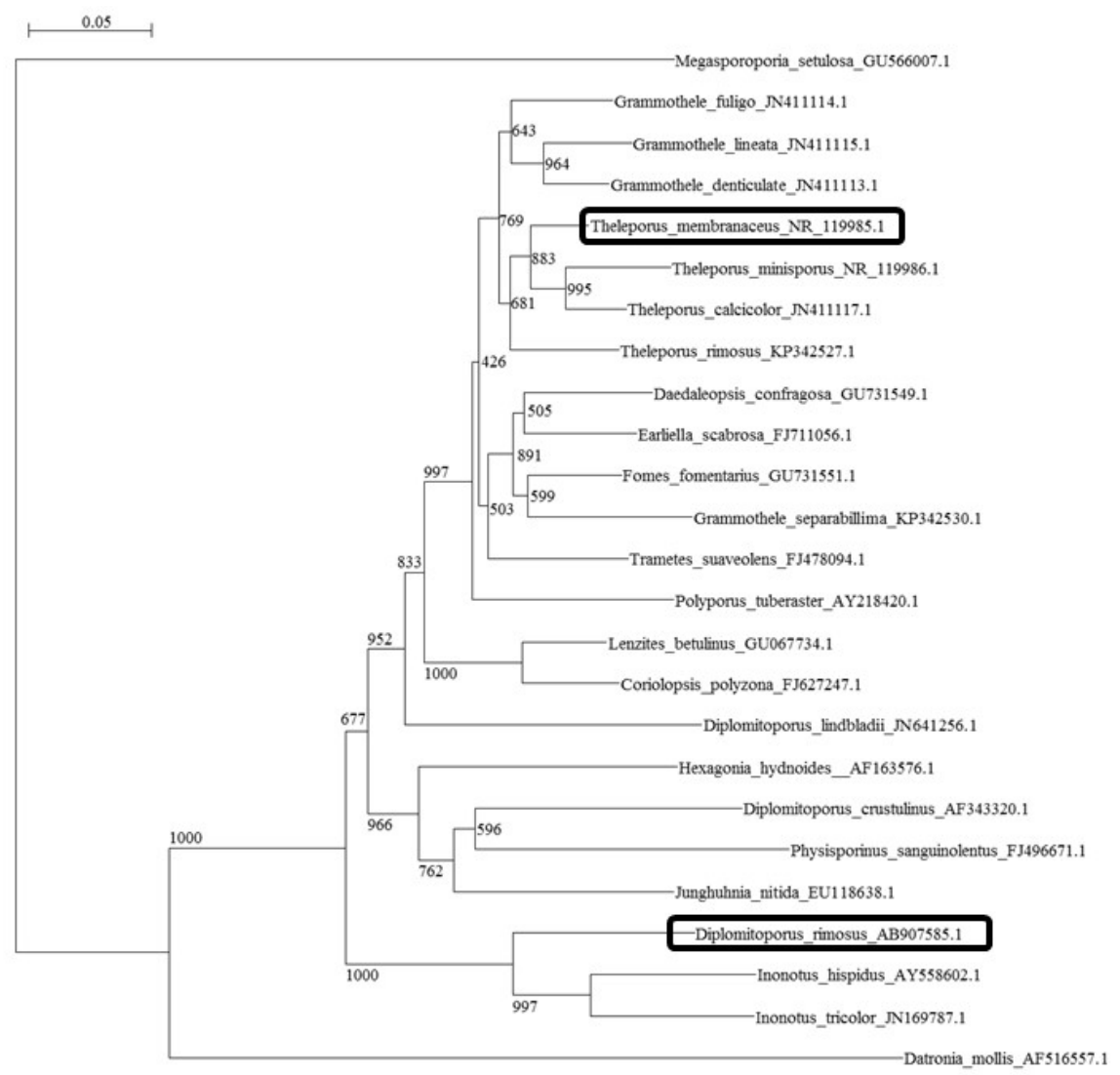

Figure 4. Phylogenetic relationship of the mycorrhizal fungi associated with Gastrodia spp., based on ITS gene sequences. GenBank accession numbers follow taxa names. Support at the nodes was computed using NJ Plot with 1000 bootstrap replicates. Mycorrhizal fungi identified from $G p$ and $G n$ protocorms are Diplomitoprus rimosus and Theleporus membranaceus, respectively

\section{Discussion}

While it was previously suggested that most MHPs associate with specific fungal species (Leake, 1994; Bidartondo, 2005; Ogura-Tsujita et al., 2012), Galeola altissima was demonstrated to form a symbiotic relationship with a variety of mycorrhizal fungi (Umata et al., 2007). Furthermore, Didymoplexis minor and D. pallens share same mycorrhizal fungi (Burgeff, 1932). In addition, fungal sharing can be also detected in Burmannia championii and B. cryptopetala (Suetsugu et al. 2014). Similarly, mycorrhizal fungi associated with $G p$ or $G n$ can form a symbiotic relationship with Gc (Tashima et al., 1978). These findings suggest that plants of 
the same genus can share mycorrhizal fungi. Mycenaceae, Masasmiaceae, Ceratobasidiaceae, and Polyporaceae were previously identified as candidate mycorrhizal fungi associated with Gastrodia spp. (Kinoshita et al., 2016). Based on our current findings, we propose that Polyporaceae associates with $G p$ and $G n$, Mycenaceae associates with $G c$, and different Gastrodia spp. can associate with the same species of mycorrhizal fungus.

Furthermore, we suggest that media derived from different preferred habitats for Gastrodia spp. can support growth of various combinations of mycorrhizal fungi and Gastrodia spp., indicating that these species potentially share many mycorrhizal fungi. These results suggest that mycorrhizal fungi used in ACSs do not need to be purified, and that the leaf and/or wood mold present in the habitats of saprophytic orchids can be used. Here we included cedar cones in our ACS media, as cones have a complex three-dimensional structure that maintains moisture and is therefore likely to promote fungal growth. Dryness reduces the viability and activity of rhizomes (Umata \& Nishi, 2010), and maintaining a moist environment is important for the artificial cultivation of Gastrodia spp. While Ge germinates optimally at a temperature of $25^{\circ} \mathrm{C}$ (Hong et al., 2004), the temperature in the natural habitat of Gastrodia spp. ranges from $<0^{\circ} \mathrm{C}$ to $>35^{\circ} \mathrm{C}$. In this study, we maintained the temperature at $20-25^{\circ} \mathrm{C}$, and this ideal environment may have accelerated the growth of Gastrodia plants.

The mycorrhizal fungi Mycena and Armillaria were previously reported to associate with Ge (Xu \& Guo, 2000). Our ACS of Gastrodia spp. may be a useful tool for analyzing mycorrhizal fungi associated with Gastrodia spp. and/or other orchids. This method could also be used to conserve Gastrodia spp. and other rare Orchidaceae plants in ex situ, many of which are endangered.

Furthermore, this method enabled us to obtain seeds from Gastrodia spp. in vitro. Using the ACS method described here, it would be possible to establish genetically homogeneous experimental lines of Gastrodia spp. It would be possible to regulate flowering time and to perform experimental crosses using different Gastrodia spp. We are currently generating inbred lines (which are now in the third generation), and plan to use these lines to perform genetic experiments in vitro.

\section{Acknowledgements}

We thank Masayuki Sato for providing us with $G c$ seeds. This work was supported by the NFD One Leaf Fund.

\section{References}

Altschul, S. F., Madden, T. L., Schaffer, A. A., Zhang, J., Zhang, Z., Miller, W., \& Lipman, D. J. (1997). Gapped BLAST and PSI-BLAST: A new generation of protein database search programs. Nucleic Acids Res., 25, 3389-3402. https://doi.org/10.1093/nar/25.17.3389

Bidartondo, M. I. (2005). The evolutionary ecology of mycoheterotrophy. New Phytol., 167, 335-352.

Burgeff, H. (1932). Saprophytismus und Symbiose. Gustav Fischer, Jena, Germany.

Chung, S. W., \& Hsu, T. C. (2006). Gastrodia shimizuana, a new record of Gastrodia (Orchidaceae) in Taiwan. Taiwania., 51, 50-52.

Dearnaley, J. D. W., \& Bougoure, J. J. (2010). Isotopic and molecular evidence for saprotrophic Marasmiaceae mycobionts in rhizomes of Gastrodia sesamoides. Fungal Ecology, 3, 288-294. https://doi.org/10.1016/ j.funeco.2009.11.003.

Fukunaga, H., Sawa, S., \& Sawa, Y. (2008). Distribution of Gastrodia nipponica, G. confusa and G.pubilabiata (Orchidaceae) in Shikoku, Japan. Bunrui, 8, 141-147. (in Japanese).

Garay, L. A., \& Sweet, H. R. (1974). Orchids of Southern Ryukyu Islands. Botanical museum, Harvard University, Massachusetts.

Gardes, M., \& Bruns, T. D. (1993). ITS primers with enhanced specificity for basidiomycetes--application to the identification of mycorrhizae and rusts. Mol Ecol., 2, 113-118. https://doi.org/10.1111/j.1365 -294X .1993.tb00005.x.

Hatusima, S. (1975). Flora of the Ryukyus, Added and Corrected. Okinawa Association of Biology Education. Naha. (in Japanese).

Honda, M. \& Tuyama, T. (1939). G. nipponica can be divided in to two. J. Jap. Bot. (in Japanese with Latin description and diagnosis), 15, 659 .

Hong, I. P., Nam, S. H., Jung, I. Y., Sung, G. B., Nam, H. W., Cheong, J. C., \& Lee, M. W. (2004). Studies on the conditions of seed germination of Gastrodia elata. Korean J. Mycol., 32, 39-44. 
Hynson, N. A., \& Bruns, T. D. (2009). Evidence of a myco-heterotroph in the plant family Ericaceae that lacks mycorrhizal specificity. Proceedings of the Royal Society of London B: Biological Sciences, 276(1675), 4053-4059. https://doi.org/10.1098/rspb.2009.1190

Kinoshita, A., Ogura-Tsujita, Y., Umata, H., Sato, H., Hashimoto, T., \& Yukawa, T. (2016). How do fungal partners affect the evolution and habitat preferences of mycoheterotrophic plants? A case study in Gastrodia. Am. J. Bot., 103, 207-220.

Kobayashi, S., \& Yukawa, T. (2001). Rediscovery of Gastrodia shimizuana Tuyama (Orchidaceae) on Iriomote Island, Japan. Acta Phytotax. Geobot., 52, 49-55.

Kusano, S. (1911). Gastrodia elata and its symbiotic association with Armillaria mellea. College of Agriculture. Imperial University of Tokyo, 5.

Larkin, M. A., Blackshields, G., Brown, N. P., Chenna, R., McGettigan, P. A., McWilliam H., \& Higgins, D. G. (2007). Clustal W and Clustal X version 2.0. Bioinformatics, 23, 2947-2948. https://doi.org/10.1093/ bioinformatics/btm 404 .

Leake, J. R. (1994). The biology of myco-heterotrophic (saprophytic) plants. New Phytol., 127, 171-216. https://doi.org/10.1111/j.1469-8137.1994.tb04272.x.

Lee, S. B., Milgroom, M. G., \& Taylor, J. W. (1988). A rapid, high yield mini-prep method for isolation of total genomic DNA from fungi. Fungal Genet. Newsl., 35, 23-24. https://doi.org/10.4148/1941-4765.1531.

Martos, F., Dulormne, M., Pailler, T., Bonfante, P., Faccio, A., Fournel, J., \& Selosse, M. A. (2009). Independent recruitment of saprotrophic fungi as mycorrhizal partners by tropical achlorophyllous orchids. New Phytol., 184, 668-681.

Ogura-Tsujita, Y., Gebauer, G., Hashimoto, T., Umata, H., \& Yukawa, T. (2009). Evidence for novel and specialized mycorrhizal parasitism: the orchid Gastrodia confusa gains carbon from saprotrophic Mycena. Proc. Biol. Sci., 276, 761-767. https://doi.org/10.1098/rspb.2008.1225.

Ogura-Tsujita, Y., Yokoyama, J., Miyoshi, K., \& Yukawa, T. (2012). Shifts in mycorrhizal fungi during the evolution of autotrophy to mycoheterotrophy in Cymbidium (Orchidaceae). Am. J. Bot., 99, 1158-1176. https://doi.org/10.3732/ajb.1100464.

Paul, K., \& Molvray, M. (2005). Gastrodia. In A. M. Pridgeon, P. J. Cribb, M. W. Chase \& F. M. Rasmussen (Eds.), Genera Orchidacearum, Oxford University Press, Oxford, England. 4, 444-447.

Roy, M., Watthana, S., Stier, A., Richard, F., Vessabutr, S., \& Selosse, M. A. (2009). Two mycoheterotrophic orchids from Thailand tropical dipterocarpacean forests associate with a broad diversity of ectomycorrhizal fungi. BMC biology, 7(1), 51. https://doi.org/10.1186/1741-7007-7-51.

Sawa, Y. (1980). Spontaneous orchids in the intermediate zone of Kochi Pref. Res. Rep. Kochi Univ. Nat. Sci., 29, 59-71. (In Japanese with Latin description).

Smith, S. E., \& Read, D. J. (2008). Mycorrhizal symbiosis, 3rd ed. Academic Pres., London, UK.

Suetsugu, K. (2012). A new form of Gastrodia confusa (Orchidaceae). Journal of Phytogeography and Taxonomy, 59, 125-126.

Suetsugu, K. (2013). Gastrodia takesimensis (Orchidaceae), A new mycoheterotrophic species from Japan. Ann. Bot. Fenn., 50, 375-378.

Suetsugu, K. (2014). Gastrodia flexistyloides (Orchidaceae), a new mycoheterotrophic plant with complete cleistogamy from Japan. Phytotaxa., 175, 270-274.

Suetsugu, K. (2015a). First record of the mycoheterotrophic orchid Gastrodia uraiensis (Orchidaceae) from Yakushima Islands, Japan. Acta Phytotax Geobot, 66, 193-196.

Suetsugu, K. (2015b). The mysterious life of plants that have lost their photosynthetic ability and eat fungi. Bunrui, 15, 99-108. (in Japanese).

Suetsugu, K. (2016). Gastrodia kuroshimensis (Orchidaceae: Epidendroideae: Gastrodieae), a new mycoheterotrophic and complete cleistogamous plant from Japan. Phytotaxa, 278, 265-272.

Suetsugu, K. (2017). Two new species of Gastrodia (Gastrodieae, Epidendroideae, Orchidaceae) from Okinawa Island, Ryukyu Islands, Japan. Phytotaxa, 302, 251-258. 
Suetsugu, K., \& Kato, M. (2014). Evolution of life history traits suited to mycoheterotrophic life style with special reference to pollination biology. BSJ-Review, 5, 93-109. (in Japanese).

Suetsugu, K., Nakayama, M., Watanabe, T., Watanabe, H., \& Yokota, M. (2012). The northernmost locality of Gastrodia shimizuana (Orchidaceae). J. Jap. Bot., 87, 62-64.

Suetsugu, K., Nakayama, M., Watanabe, T., Watanabe, H., Yamamoto, T., \& Yokota, M. (2013). First record of the mycoheterotrophic plant Gastrodia clausa (Orchidaceae) from Okinawa Island, Ryukyu Islands, Japan. Acta phytotax Geobot., 64, 123-126.

Sugino, T. \& Suzuki. I. (1985). Distribution and ecology of Codonanthus species in the Enshu region, Japan. Enshu no Shizen, 8, 29-41. (in Japanese).

Sugino, T. (1983). Habitat of Codonanthus species in the Enshu region, Japan. Enshu no Shizen, 6, 21-29. (in Japanese).

Tashima Y., Terashita, T., Umata, H. \& Matsumoto, M. (1978). In vitro development from seed to flower of Gastrodia verrucosa under fungal symbiosis. Trans. Mycol. Soc. Jap., 19, 449-453.

Tuyama, T. (1939). Plantæ Boninenses Novæ vel Criticæ. XII. Bot. mag. Tokyo. (Latin description and diagnosis), 53, 1-7.

Tuyama, T. (1941). Notes on Genus Gastrodia of southeastern Asia. J Jap Bot., 17, 581-582.

Tuyama, T. (1952). Notes on Gastrodia of Japan (1). J. Jap. Bot., 27, 19-26.

Tuyama, T. (1956). Notes on Gastrodia of Japan (2). J. Jap. Bot., 31, 77-83.

Tuyama, T. (1966). Notes on Gastrodia of Japan (3). J. Jap. Bot., 41, 339-346.

Tuyama, T. (1967). Notes on Gastrodia of Japan (4). J. Jap Bot, 42, 230-236.

Tuyama, T. (1982). A new Gastrodia from the Ryukyus. Acta Phytotax. Geobot., 33, 380-382.

Umata, H. \& Nishi, M. (2010). Ecological characteristics and water supply effect on in situ conservation in Gastrodia nipponica and G. pubilabiata, the endangered myco-heterotrophic orchids. Res. Bull. Kagoshima Univ., 37, 137-149.

Umata, H., Kaneko, M., Miyagi, T. \& Nakahira, Y. (2007). The application and Utilization of fungi for the propagation of the endangered achlorophyllous plant Erythrorchis ochobiensis (Hayata) Garay (Orchidaceae) in natural situations. Res. Bull. Kagoshima Univ. For., 35, 31-48.

Umata, H., Yamauchi, H. \& Hashimoto, T. (2000). In Vitro Culture of a Myco-heterotrophic Orchid Gastrodia pubilabiata with a Mycorrhizal Symbiont of G. verrucosa. Res. Bull. Kagoshima Univ. For., 28, 27-30.

Wu, Z. H., Wang, T. H., Huang, W. \& Qu, Y. B. (2001). A simplified method for chromosome DNA preparation from filamentous Fungi. Mycosystema., 20, 575-577.

Xu, J. \& Guo, S. (2000). Retrospect on the research of the cultivation of Gastrodia elata Bl., a rare traditional Chinese medicine. Chinese Med. J., 113, 686-692.

\section{Copyrights}

Copyright for this article is retained by the author(s), with first publication rights granted to the journal.

This is an open-access article distributed under the terms and conditions of the Creative Commons Attribution license (http://creativecommons.org/licenses/by/4.0/). 